\title{
Variations in the Properties and Morphology of Cysts of Acanthamoeba castellanii
}

\author{
By MICHAEL P. STRATFORD AND ALAN J. GRIFFITHS \\ Microbiology Department, University College, Cardiff CF1 1 XP
}

(Received 5 April 1978)

\begin{abstract}
The structure and behaviour of cysts of a single strain of Acanthamoeba castellanii produced in different cultural conditions were investigated. There appeared to be a gradation from the type of cysts with a wrinkled cyst wall, which were produced in monoxenic culture and in replacement medium, to the smooth, refractile cells, lacking a distinct wall, which were produced in a growth medium supplemented with $\mathrm{MgCl}_{2}$. All the cyst types exhibited depressed metabolic activity and only differed in the degree to which they were resistant to heating and low temperatures. The results are discussed in relation to the use of cyst structure as a criterion for classifying the various species of Acanthamoeba.
\end{abstract}

\section{INTRODUCTION}

The cysts produced by amoebae at various stages of their life-cycles, particularly under conditions of starvation, are features of some taxonomic importance. This is especially true for the small soil and freshwater amoebae of the genera Acanthamoeba, Hartmannella and Mayorella. Despite reports that there can be 'considerable' variation in the form of the mature cysts, relatively small differences in their structure are still important criteria for the identification of some species of Acanthamoeba (Page, 1967, 1976).

In this study a comparison has been made of the cysts produced by a strain of $A$. castellanii under different conditions of axenic and monoxenic culture, and the results are discussed in relation to the use of cyst structure as a taxonomic criterion.

\section{METHODS}

The organism and its culture. The Neff isolate of Acanthamoeba castellanii was obtained from Mrs K. M. G. Adam, Zoology Department, University of Edinburgh, and was grown axenically in $4 \%(w / v)$ Mycological Peptone (Oxoid). Cultures $(50 \mathrm{ml})$ were incubated $\left(30^{\circ} \mathrm{C}\right)$ in $250 \mathrm{ml}$ conical flasks on a shaking water-bath and subcultures were made with $5 \mathrm{ml}$ from a $2 \mathrm{~d}$ culture.

Production of cysts. Cysts were obtained in four ways: (i) by the replacement method (Griffiths \& Hughes, 1969) which involves incubating an exponentially growing culture of amoebae in $50 \mathrm{~mm}-\mathrm{MgCl}_{2}$; (ii) by adding $\mathrm{MgCl}_{2}$ (final concentration $50 \mathrm{~mm}$ ) to $4 \%(\mathrm{w} / \mathrm{v}$ ) Oxoid Mycological Peptone (Griffiths \& Hughes, 1969); (iii) by adding $\mathrm{MgCl}_{2}$ (final concentration $50 \mathrm{~mm}$ ) to PGY growth medium [consisting of (g 1-1): Difco Proteose Peptone, 7.5; Difco yeast extract, 7.5; glucose, 15.0]; and (iv) following growth in monoxenic culture. In the monoxenic cultures the amoebae were grown with Klebsiella aerogenes on a solidified medium containing $\left(\mathrm{g}^{-1}\right)$ : Oxoid Bacteriological Peptone, $1 \cdot 0$; Oxoid yeast extract, $0 \cdot 1$; glucose, $1 \cdot 0$; Oxoid agar no. 2, 20.0. An overnight culture of the bacteria was grown on the above medium (without the agar) and $0.1 \mathrm{ml}$ of this was mixed with $0.05 \mathrm{ml}$ of a $2 \mathrm{~d}$ amoeba culture which had been grown axenically as described above. The mixed suspension was spread over the surface of the solidified medium and incubated for 5 to $6 \mathrm{~d}$. The cysts were then collected by flooding the plates with sterile distilled water and scraping the surface of the agar with a glass spreader. All cultures were incubated at $30^{\circ} \mathrm{C}$.

Electron microscopy. Cysts were fixed for $3 \mathrm{~h}$ in glutaraldehyde $(3 \%, \mathrm{w} / \mathrm{v}$, in $100 \mathrm{~mm}$-phosphate buffer, $\mathrm{pH} 6.8)$ and postfixed for $1.5 \mathrm{~h}$ in osmium tetroxide $(2 \%, \mathrm{w} / \mathrm{v}$, in $100 \mathrm{~mm}$-phosphate buffer, $\mathrm{pH} 6.8)$. Fixed 
cells were dehydrated in ethanol and washed in propylene oxide before embedding in Araldite. To allow a more effective penetration of the embedding medium, the cells were placed in a mixture of equal parts of Araldite and propylene oxide which was allowed to evaporate overnight at room temperature. The cells were then placed in a fresh Araldite mixture and allowed to stand for 2 to $3 \mathrm{~d}$ at room temperature; the Araldite was then polymerized at $60{ }^{\circ} \mathrm{C}$ for $2 \mathrm{~h}$. Sections were cut on a Reichert ultramicrotome and stained with lead acetate $(2 \%, w / v$, in a saturated solution of uranyl acetate).

Chemical composition of cysts. Protein was measured in a fraction insoluble in trichloroacetic acid but soluble in alkali, cellulose was measured as an alkali-insoluble residue and RNA was measured as pentose in the fraction soluble in hot trichloroacetic acid (Griffiths \& Hughes, 1969).

Measurement of respiration rates. Oxygen consumption of the cysts was measured in a Gilson respirometer (Gilson Medical Electronics, Wisconsin, U.S.A.). The respirometer flasks contained $5 \mathrm{mg}$ dry weight of the cysts suspended in $2.8 \mathrm{ml}$ Mycological Peptone $(4 \%, \mathrm{w} / \mathrm{v})$. The gas phase was air; $\mathrm{CO}_{2}$ was absorbed by $0.2 \mathrm{ml} \mathrm{KOH}(20 \%, \mathrm{w} / \mathrm{v})$. The flasks were incubated at $30^{\circ} \mathrm{C}$ and shaken at 150 cycles $\mathrm{min}^{-1}$.

Preparation of cyst suspensions. The cysts which were produced axenically were collected by centrifuging $(500 \mathrm{~g})$ and washed with sterile distilled water. Those from monoxenic cultures were washed with sterile distilled water and then incubated with $1 \mathrm{M}-\mathrm{HCl}$ for $24 \mathrm{~h}$. They were then washed repeatedly with sterile water until the washings were neutral. This treatment was sufficient to remove the bacteria which adhere to cysts in monoxenic cultures, as no traces of bacterial growth were observed in subsequent cultures inoculated with cysts prepared in this way and incubated in Mycological Peptone. Also, when cyst suspensions, after the acid and water washings, were spread on plates of the solidified medium described above, no bacterial growth was observed after incubating for a week at $30^{\circ} \mathrm{C}$.

Survival of cysts. The washed cysts were resuspended in sterile distilled water and after 1 month at laboratory temperature the suspension was centrifuged and the pellet was resuspended in $4 \%(\mathrm{w} / \mathrm{v})$ Mycological Peptone and incubated at $30^{\circ} \mathrm{C}$. Suspensions of cysts in water were used to determine the effect of heating on cyst survival; the suspension was incubated in a water-bath $(30 \mathrm{~min})$ at the appropriate temperature before centrifuging and resuspending in Mycological Peptone. The pellets of washed cysts were also stored at $-25^{\circ} \mathrm{C}$ for 1 month; the frozen cells were thawed at laboratory temperature before resuspension in Mycological Peptone.

\section{RESUI,TS}

\section{Morphology of the cyst types}

Of the four cyst types examined, those produced in Mycological Peptone supplemented with $\mathrm{MgCl}_{2}$ differed markedly from the others. They were smooth in outline and lacked any semblance of a cyst wall. Cellulose was, however, detectable as an alkali-insoluble residue and comprised 5 to $6 \%$ of the dry weight of the cysts compared with 22 to $27 \%$ for the other cyst types. These cells were also highly refractile. Electron micrographs (Fig. 1a) showed a prominent nucleus and confirmed the absence of the wall layers which are characteristic of cysts (Fig. 1b). Perhaps the most noticeable feature was the presence of numerous vacuoles, densely packed together, which probably contribute to the refractility which is so obvious under the light microscope.

The cysts which were produced in the replacement medium (Fig. 1 b) were very similar to those described by Bowers \& Korn (1969). There was a prominent cyst wall which was wrinkled, giving the cyst a stellate appearance in sections. Autolysosomal material was embedded in the wall layers and plugs of electron-dense material closed the pores through which excystation takes place and which are clear discontinuities in the wall structure. The cytoplasm was dense, a possible effect of shrinkage during preparation of the material for electron microscopy, but there were no discernible organelles, with the possible exception of some membrane-bound structures which were suggestive of autophagosomes. The cysts which were produced in monoxenic culture were, in every respect, similar in structure to the replacement medium cysts.

The fourth cyst type, produced in PGY medium supplemented with $\mathrm{MgCl}_{2}$, could be considered to represent a form intermediate between the replacement medium cysts and the refractile cells (Fig. 1c). The cysts had a smooth outline but were clearly bounded by a wall. At higher magnifications, the wall was seen to be much thinner than that of the stellate cysts (Fig. $1 d$ ). Nuclei were prominent in the cytoplasm as well as a large number of empty, membranous vacuoles. Autophagic vacuoles were also to be seen but these were generally small and could represent degraded mitochondria. 

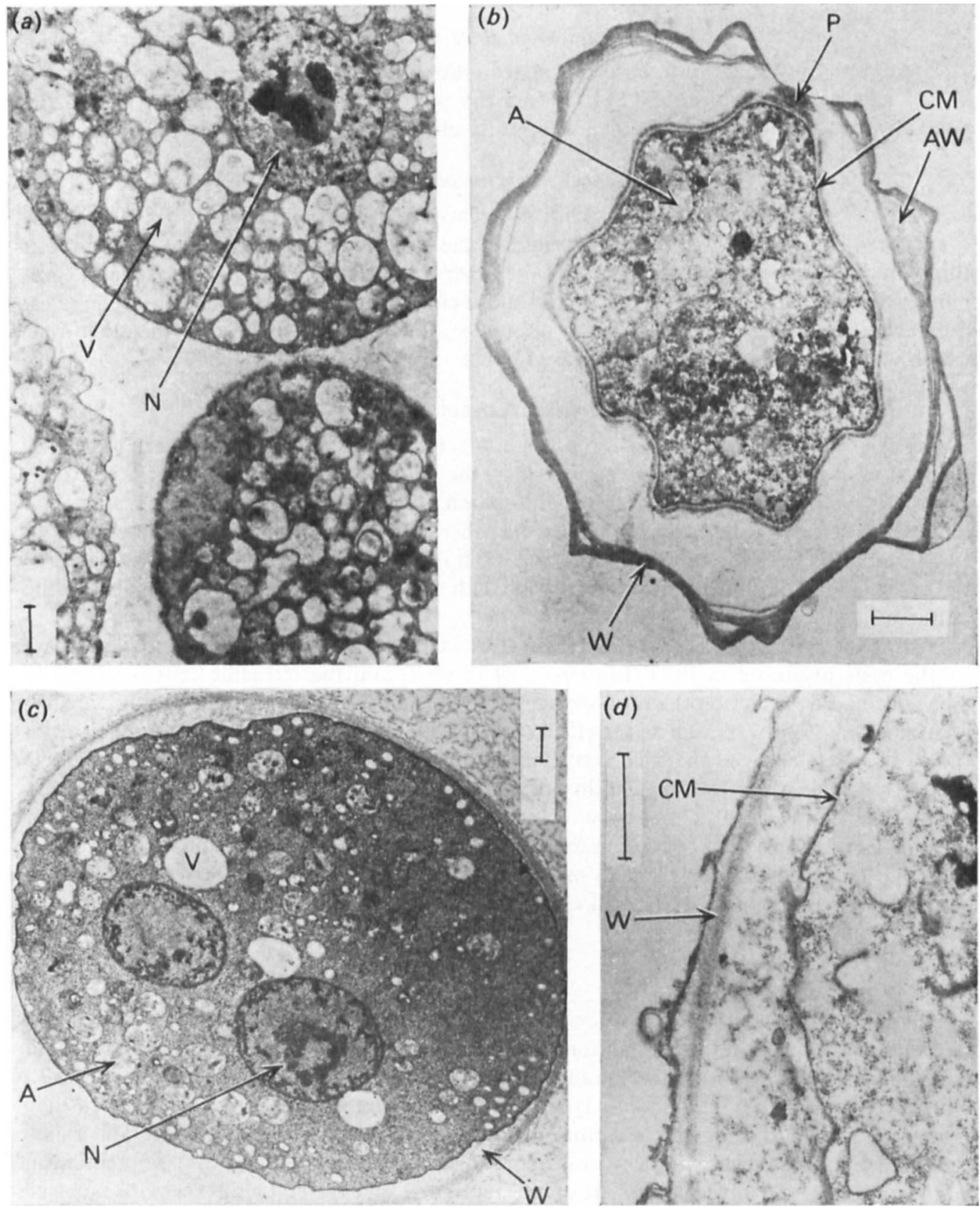

Fig. 1. Electron micrographs of cyst types of Acanthamoeba castellanii: (a) refractile cells produced in $4 \%(\mathrm{w} / \mathrm{v})$ Mycological Peptone supplemented with $50 \mathrm{mM}-\mathrm{MgCl}_{2} ;(b)$ cyst from replacement medium; $(c)$ cyst produced in PGY/Mg; $(d)$ detail of wall of $(c)$. Abbreviations: A, autophagosome; $\mathrm{AW}$, autophagosomal material embedded in cyst wall; $\mathrm{CM}$, region of cell membrane; $\mathrm{N}$, nucleus; $\mathrm{P}$, pore; V, vacuole; W, wall layers. Bar markers represent $1 \mu \mathrm{m}$. 


\section{Respiration rates of cysts}

There were only slight differences in the respiration rates of the four cyst types. The $Q_{\mathrm{o}_{2}}$ values ranged from 0.67 to $1.42 \mu \mathrm{O}_{2}$ (mg dry wt) ${ }^{-1} \mathrm{~h}^{-1}$. All were less active than the vegetative amoebae in which the $Q_{\mathrm{O}_{2}}$ is typically of the order of $30 \mu 1 \mathrm{O}_{2}(\mathrm{mgdry} \mathrm{wt})^{-1} \mathrm{~h}^{-1}$.

\section{Differences in chemical composition}

There did not appear to be significant differences in the protein contents of the various cyst types $(42 \cdot 2$ to $50 \cdot 2 \%$ of the dry weight of the cysts) but the refractile cells had about three times the concentration of RNA of the other cyst types $(8.7 \%$ of the dry weight compared with 2.8 to $3.2 \%$ ). It was in the cellulose content that the cells showed the greatest differences. The refractile cells had only about $25 \%$ of the cellulose found in the other cysts which were all similar in their cellulose contents.

\section{Survival and resistance of cysts}

The cysts had different excystation times in 4\% (w/v) Mycological Peptone as judged by the first appearance of vegetative amoebae in the cultures. The refractile cells and monoxenic cysts exhibited the most rapid germination with trophozoites appearing after $60 \mathrm{~h}$ incubation compared with 72 to $84 \mathrm{~h}$ for the other cyst types. In view of the time taken to excyst, cultures were examined at intervals of $6 \mathrm{~h}$ in these and subsequent experiments. All the cysts appeared to have germinated within $24 \mathrm{~h}$ of the first appearance of amoebae in the cultures.

Storing the cysts in water at room temperature increased the time required for excystation by the cysts produced in PGY/Mg (from 84 to $96 \mathrm{~h}$ ) and the refractile cells (from 60 to $84 \mathrm{~h}$ ) but had no effect on the monoxenic cysts $(60 \mathrm{~h})$ or the cysts produced in the replacement medium $(72 \mathrm{~h})$. As well as the effect of generally lengthening the germination times of the cysts which survived the treatments, storage at the lower temperature of $-25^{\circ} \mathrm{C}$ for 1 month resulted in the loss of viability of the refractile cells. None of the cysts survived heating for $30 \mathrm{~min}$ at $70^{\circ} \mathrm{C}$ but only the refractile cells were killed by heating at $60^{\circ} \mathrm{C}$ for $30 \mathrm{~min}$. The general effect of heating the cysts was again to increase the time taken to excyst such that in the case of replacement medium cysts, for example, amoebae were not seen in germinating cultures until $120 \mathrm{~h}$ had elapsed after the cysts had been heated at $60^{\circ} \mathrm{C}$.

\section{DISCUSSION}

The gradation which appears to exist from the mature, stellate cyst to the smooth and refractile cell suggests that encystation in $A$. castellanii is not an all-or-nothing event and that the process of cyst formation is susceptible to environmental influences. It is, however, worth noting that the different cyst types were unique to the conditions under which they were produced so that no single culture contained more than one type of cyst. This raises the problem of the biochemical controls operating during the amoeba-to-cyst differentiation and requires further investigation. It could be argued that the refractile cells are not true cysts, but their depressed metabolism, their ability to remain viable after storage at laboratory temperature and their resistance to elevated temperatures which are usually lethal to vegetative cells sets them aside as, at least, somewhat specialized structures.

Far more important from the taxonomic standpoint are the resemblances between the cysts produced in these experiments with those normally associated with other species of soil and freshwater amoebae. For example, Page (1976) distinguishes between A. castellanii and $A$. polyphaga on the differences in cyst structure which are based essentially on the degree of contact between the wall layers and on whether the wall is wrinkled or smooth. We have produced all these forms in a single strain of $A$. castellanii simply by modifying the environment in which they were produced. The presence of pores through which excystation 
can take place without digestion of the cyst wall is also an important taxonomic feature in Acanthamoeba, distinguishing this genus from Hartmannella. Two of the cyst types produced in our experiments, the refractile cells and the PGY/Mg cysts, appeared to lack pores in the walls or outer layers. Empty cysts were, however, seen in the excysted cultures of the $\mathrm{PGY} / \mathrm{Mg}$ cysts, suggesting that amoebae had emerged without dissolution of the wall layers; these were not seen in the cultures of the refractile cells after germination. This problem also requires further study in view of the reported existence of cellulase in $A$. castellanii (Deichmann \& Jantzen, 1977).

In view of the results of these experiments the use of differences in cyst structure for classifying amoebae must be open to question.

\section{REFERENCES}

BOWERs, B. \& Korn, E. D. (1969). The fine structure of Acanthamoeba castellanii (Neff strain). II. Encystment. Journal of Cell Biology 41, 786-805.

Deichmann, U. \& Jantzen, H. (1977). Das Cellulaseenzymsystem während Wachstum und Entwicklung von Acanthamoeba castellanii. Archives of Microbiology 113, 309-313.

Griffirhs, A. J. \& Hughes, D. E. (1969). The physiology of encystment of Hartmannella castellanii. Journal of Protozoology 16, 93-99.

PAGE, F. C. (1967). Re-definition of the genus Acanthamoeba with descriptions of three species. Journal of Protozoology 14, 709-724.

PAGE, F. C. (1976). An Illustrated Key to Freshwater and Soil Amoebae. Scientific Publication 34. Ambleside, Cumbria: Freshwater Biological Association. 